\title{
Analysis of land cover change and its driving forces in a desert oasis landscape of Xinjiang, northwest China
}

\author{
T. Amuti ${ }^{1,2,4}$ and G. Luo ${ }^{1,3}$ \\ ${ }^{1}$ State Key Laboratory of Desert and Oasis Ecology, Xinjiang Institute of Ecology and Geography, \\ Chinese Academy of Sciences, Urumqi 830011, Xinjiang, China \\ ${ }^{2}$ The Graduate University of the Chinese Academy of Sciences, Beijing 100049, China \\ ${ }^{3}$ XIEG-UCR International Center for Arid Land Ecology, Chinese Academy of Sciences, Urumqi 830011, \\ Xinjinag, China \\ ${ }^{4}$ School of Geographic Science and Tourism, Xinjiang Normal University, Urumqi, 830054, Xinjiang, China \\ Correspondence to: G. Luo (luogp@ms.xjb.ac.cn)
}

Received: 9 July 2014 - Published in Solid Earth Discuss.: 28 July 2014

Revised: 6 October 2014 - Accepted: 8 October 2014 - Published: 18 November 2014

\begin{abstract}
The combined effects of drought, warming and the changes in land cover have caused severe land degradation for several decades in the extremely arid desert oases of southern Xinjiang, northwest China. Land cover classifications of Landsat images in 1990, 2000 and 2008 were performed based on the multistage supervised classification scheme using the maximum likelihood classifier integrated with conventional vegetation and soil indexes, which improved overall accuracies by $4-5 \%$ compared to the standard classification method. Based on the detection of changes in land cover during 1990-2008 using remote sensing (RS) and a geographic information system (GIS), it can be found that the oasis significantly $(+35 \%)$ increased, while the area of ecotone decreased $(-43 \%)$. The major trends of the land cover changes were the notable growth of the oasis and the reduction of the desert-oasis ecotone. These changes were mainly a result of the intensified human activities such as land and water exploitation as well as overgrazing. The results of this study indicate that the oasis environment will be deteriorated by increase in potential areas of land degradation if the trend of desert moving further inward and the shrinking of the ecotone continues over the next decades.
\end{abstract}

\section{Introduction}

Land use and land cover changes are among the most important human-induced alterations of the Earth's land surface (Dickenson, 1995; Lambin et al., 2000). The change of land use and land cover not only is closely related to the ecosystem services but also has influences on the climate, biodiversity and evolution of the ecological environment (Kalluri, 2002; Wang et al., 2006; Qi et al., 2007). In arid environments, soils suffer from high erosion rates due to wind, drought, sparse vegetation cover and the pressure of human activities (Lambin et al., 2001; Ziadat and Taimeh, 2013). In these environments, soil loss and vegetation deterioration have increasingly been accelerated by improper use of land and water resources (Geist and Lambin, 2002; Ma et al., 2002; Lei et al., 2006; Wei et al., 2008; Zhao et al., 2013). The conversion of natural vegetation to cropland and overgrazing will therefore affect the storage of soil organic matter and soil nutrients (Li et al., 2005; Yu et al., 2012; Bruun et al., 2013). During the last few decades, land degradation associated with land use/cover changes in dryland ecosystems have been the focus of the study of land/vegetation processes and climatic change (Reid et al., 2000; Masoud and Koike, 2006; Reynolds et al., 2007; John et al., 2009; Bakr et al., 2010; Tsegaye et al., 2010; Schulz et al., 2010).

China is one of the countries most severely impacted by desertification, and $34.6 \%$ of its territory is comprised of drylands subject to the potential of desertification (Wang et 
al., 2012), among which the desertified land located in the intrazonal landscape oases surrounded by deserts accounts for a significant proportion of the arid and semi-arid regions in China (Zhang et al., 2003). The desertification in these areas is mainly caused by wind erosion, water erosion, soil salinization and degradation by human factors. The oases located in the Xinjiang Uyghur Autonomous Region of northwest China, as the areas experiencing severe drought and sandy desertification, have undergone remarkable changes in land cover with increasing human activities over the last decades, largely reflecting the general trend of oasis expansion into the transitional zone between oasis and desert (Hu et al., 2001; Dittrich et al., 2010). Desert-oasis ecotone, a narrow belt between desert and oasis, functions as a boundary and corridor between desert and oasis ecosystems, controlling the flux of energy and nutrients as well as being a biotic exchange between desert and oasis (Wang et al., 2007). Under the disturbance of the arid climate and improper human intervention, the desert-oasis ecotone, being the most sensitive area to human activities such as land and water exploitation (Neilson, 1993), has encountered vital depletion of natural vegetation in the process of both oasification and desertification (Han and Meng, 1999; Wang et al., 2006; Li and Tiyip, 2008). The stability of oasis ecosystems is affected by both desertification in the oases-desert ecotone and salinization in the interior of the oasis (Hamid et al., 2002). These changes have led to drought and desertification and, consequently, have hindered the development of sustainable agriculture, resulting in an urgent need to understand the oasis-desert interaction and processes (Liu et al., 2007). Coupled with changing climate, rapid population growth, economic development and unsustainable land use have increasingly generated pressure on existing land and other resources, which has resulted in remarkable changes and modifications in the spatial distribution of land use/cover in the oases. Despite various attempts to rehabilitate the degraded land and ensure the ecological balance of the oases, the sandy desertification and salinization of the land are the most serious environmental problems occurring widely in these rangelands (Jia et al., 2004; Yang et al., 2005; Zhou et al., 2010), thus threatening the stability and sustainable development of the entire region.

Previous studies on the land use/cover changes of oases in Xinjiang have mainly focused on farmland expansion, land use change, vegetation cover, soil properties, land desertification and their environmental impacts (Li et al., 2004a; Wang, 2004; Cheng et al., 2006; Tang et al., 2007; Wang et al., 2009; Luo et al., 2010; Liu et al., 2010), including the description of severe reductions of desert-oasis ecotones due to desertification and the loss of natural vegetation (Ding et al., 2006; Sun et al., 2007). These studies have generally described the processes and trends of land use/cover changes in desert oasis landscapes. However, they have not provided detailed information on quantitative changes of land cover temporally and spatially, and few attempts have been made to identify changing patterns and trajectories of ecotones between oases and deserts. There has been little research acknowledging the ecological importance of the desert-oasis ecotones and the significance of links between the mechanism of special zones and the environmental evolution of oases. For this purpose, a typical irrigation and agriculture oasis in extremely arid regions of northwest China, the desert oasis in Hotan River basin, was selected as a case study. In this geographically isolated area populated by a rural ethnic minority (more than $80 \%$ ), the demographic factors show considerably negative environmental/ecological impacts on the arid ecosystem. The integrated analysis is therefore necessary for better understanding of the process trends and driving forces behind land cover changes in this region. This would allow us to identify how humans have changed land cover and the ways oases, deserts and ecotones interact under the current climate and human forces.

To gain a systematic understanding of the processes of land cover changes in the study area, an integrated method of remote sensing (RS) with a geographic information system (GIS) was used (Alphan, 2012). The method includes supervised classification and post-classification comparison techniques in RS and GIS spatial analysis, which have been widely used to clarify the magnitude, location and patterns of land cover changes (Lambin et al., 2003; Coppin et al., 2004; Lu, 2004; Serra et al., 2008). The environmental and human driving forces were analyzed to examine the causes of land cover changes in the Hotan Oasis.

The main purposes of this study are (1) to estimate spatial and temporal changes of land cover in the Hotan Oasis during 1990-2008 using remote sensing and geo-spatial techniques and (2) to identify the main driving forces and their impacts on land cover changes within the study area. This study can help toward understanding land cover dynamics and human-environment interactions in desert oasis landscapes, which is crucial for land managers to establish longterm soil conservation and restoration practices.

\section{Study area}

Hotan Oasis, which includes three counties and one city, is located in the Hotan River basin at the south of the Tarim River in southern Xinjiang. It is an extremely arid area, which covers an area of $8.05 \times 10^{6}$ ha extending within the latitudinal range $34^{\circ} 22-39^{\circ} 38^{\prime} \mathrm{N}$ and the longitudinal range $78^{\circ} 01^{\prime}-81^{\circ} 33^{\prime} \mathrm{E}$. Meanwhile, the study area is divided into three sub-regions, namely the upper reaches, middle reaches and lower reaches from south to north. It is interleaved by the Gobi Desert in the middle, Taklimakan Desert in the north and the Kunlun Mountains bordered by Tibet in the south, where droughts, sandstorms and salt alkalization are very severe. The utilization of soil and water is very low.

The Hotan Oasis falls within the category of a continental warm temperate monsoon climate with distinct seasons. The average annual temperature in the oasis plains is $12.2^{\circ} \mathrm{C}$, and 


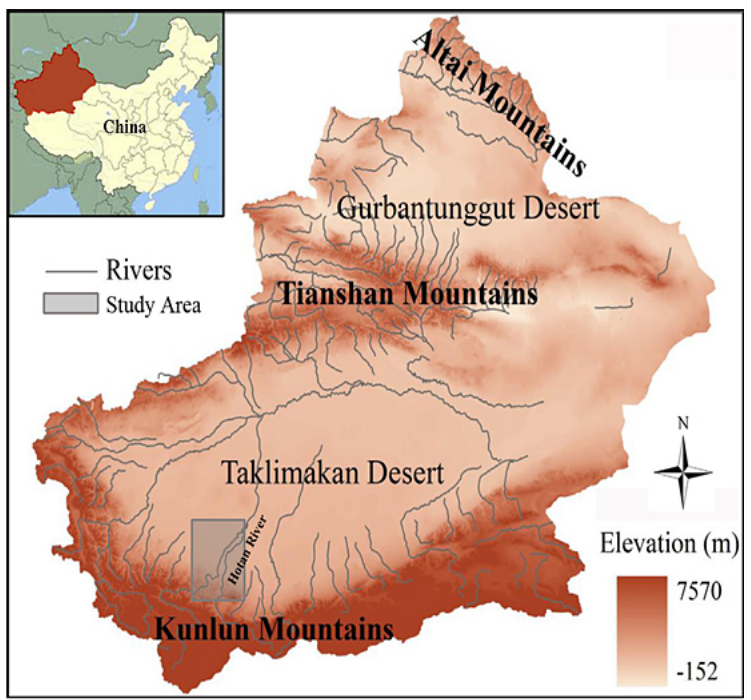

Figure 1. Sketch map of the study area.

the annual average precipitation is $35.6 \mathrm{~mm}$; however, the annual amount of evaporation is about $2602 \mathrm{~mm}$ and the annual average wind speed is $2.1 \mathrm{~m} \mathrm{~s}^{-1}$. The Hotan Oasis lies along the Hotan River, which starts from the Kunlun Mountains and crosses the alluvial-proluvial fan and fine soil plain in the north, winding its way through the Taklamakan Desert for $319.0 \mathrm{~km}$ before flowing into the Tarim River (Fig. 1). The land slopes down from south to north, where the Kunlun Mountains are generally about $6000 \mathrm{~m}$ above sea level with the highest above $7500 \mathrm{~m}$, and the desert plain with the lowest elevation point of $152 \mathrm{~m}$ below sea level. The proportional areas of southern mountains, Gobi Desert and plain oasis are 33.3, 63 and $3.7 \%$, respectively. The agricultural land accounts for $1.1 \%$ within the oasis, and it is mostly distributed in band shape alongside the river and lake. The farms are managed by the family-based "Household Contract Responsibility System" (HCRS) and are mostly less than 1 ha in size. Furthermore, the agricultural parcels are generally fragmented. The major soils that support crops and forests in the Hotan River basin are Fluvisols, Gleysols, Solonchaks, Arenosols and Anthrosols (FAO, 2006). Sand and dust storms are very common in the region during the spring and summer, which greatly influence the vegetation photosynthesis and growth. The natural vegetation, including dense shrubs and trees mixed with grasses (e.g., Populus, Tamarix or Phragmites), is mainly distributed around the oasis along the river, which can be seen as part of the oasis, as well as the desert-oasis ecotone, characterized by low diversity, sparse cover and dominance by perennial herbaceous grasses and semi-shrubs, such as Phragmites australis, Tamarix ramosissima, Karelinia caspia, Alhagi sparsifolia, etc.

\section{Materials and methods}

\subsection{Data set}

The data used to extract land cover information in this study consisted of three available Landsat TM (Thermatic Mapper) and ETM+ (Enhanced Thematic Mapper Plus) images acquired on 5 October 1990 with $28.5 \mathrm{~m} \times 28.5 \mathrm{~m}, 24$ October 2000 with $30 \mathrm{~m} \times 30 \mathrm{~m}$ and 28 September 2008 with $30 \mathrm{~m} \times 30 \mathrm{~m}$ spatial resolutions (path/row 146/34). The images with acquisition dates as close as possible to the different years (different dates in fall season) were selected to minimize problems related to the sun position and vegetation phenology. The subsets of TM/ETM+ images $(1650 \times 3300$ pixels) within the latitudinal range $36^{\circ} 52^{\prime}-38^{\circ} 02^{\prime} \mathrm{N}$ and the longitudinal range of $79^{\circ} 26^{\prime}-80^{\circ} 35^{\prime} \mathrm{E}$ covering the oasis area, a total size of $1273710 \mathrm{ha}$, in the middle reaches with an elevation ranging from 1250 to $\sim 1380 \mathrm{~m}$ were extracted for this study. A topographic map (with positional accuracy of $\pm 2.5 \mathrm{~m}$ ) and a land use map of Xinjiang Province in 1990 at a scale of $1: 50000$ provided by the Surveying and Mapping Bureau of Xinjiang was used as reference data to assist the classification and accuracy assessment of the 1990 image. The land use map was created by visual interpretation of aerial photography from 1990 in combination with fieldwork sampling. For the 2000 image classification, a multispectral $4 \mathrm{~m}$ resolution IKONOS image acquired on 20 September 2000, which covered the whole study area, was used as reference (ground truth) data. High spatial resolution imagery (QuickBird operated by DigitalGlobe) in Google Earth (GE) with a spatial resolution of $2.4 \mathrm{~m}$ acquired on 25 September 2008 was used for visual interpretation and validation of land cover imagery in 2008. Images of vegetation and soil indexes were also derived from three Landsat images and used as reference data.

In addition, socioeconomic data (e.g., population, gross domestic product (GDP) and cultivated land) from the "Xinjiang Statistical Yearbook" (1990-2010) on the county level, climatic data (i.e., precipitation and temperature) (1960-2010) from the ground meteorological station of Hotan and hydrological data from Xiaota hydrometric station in the downstream of the Hotan River and Wuluwat and Tonguzluk hydrometric station in the upstream of the Hotan River (1960-2010) were collected and used as ancillary data to explain the most relevant driving forces of land cover changes in the study area.

\subsection{Data pre-processing}

The pre-processing of each Landsat image was done with image enhancement, geo-registration, radiometric correction using ENVI 4.7 image-processing software. Each Landsat image was enhanced using linear contrast stretching and histogram equalization to better identify ground control points in geo-registration. The multi-dated images were 
geo-referenced to a common Universal Transverse Mercator coordinate system (UTM/WGS84, zone 44) based on the high-resolution IKONOS image and the 1:50000 scale topographic map with 26 ground control points (GCPs). The GCPs were used to correct the distortions on the images and map them to their true positions in ground coordinates. The GCPs were mostly selected at road intersections, bends in rivers features and the like that can be easily located. The resultant root mean square error (RMSE) of rectification was less than half a pixel $(15 \mathrm{~m})$. To make the classified land cover images comparable, the Landsat images were re-sampled to a pixel size of $30 \mathrm{~m} \times 30 \mathrm{~m}$ using the nearestneighbor method. Radiometric correction (Chen et al., 2005) was then implemented on these images to reduce the influences of errors due to sensor differences, Earth-Sun distance, solar zenith angle and atmospheric condition, which are important in multi-temporal analysis of vegetation indexes.

All hydro-climatic data and socioeconomic data are categorized and plotted to examine the changes and trends of the natural and human variables that are considered to be related to the changes of land use/cover in the Hotan Oasis during the observed time period. Integrating these data with RS and GIS analysis of land cover changes could help explain the underlying causes of the changes in land cover and provide implications for making better landscape management strategies.

\subsection{Vegetation and soil indexes}

The normalized difference vegetation index (NDVI), the soiladjusted vegetation index (SAVI) and the normalized difference salinity index (NDSI) were extracted from each geometrically and radiometrically corrected image and used as ancillary data. These data were used to improve the accuracy of the land cover classification by separating features with similar spectral properties.

NDVI (Rouse et al., 1973) is the ratio between near infrared (NIR) and red reflectance (Eq. 1) and provides an indication of vegetation growth to estimate the amount or cover of vegetation (Shippert et al., 1995; Masek et al., 2000). It was calculated as

$\mathrm{NDVI}=\frac{\mathrm{NIR}-\mathrm{Red}}{\mathrm{NIR}+\text { Red }}$

The estimation of fractional vegetation cover (FVC) can be obtained through a scaled NDVI (Carlson and Ripley, 1997) defined as

$\mathrm{FVC}=\frac{\mathrm{NDVI}-\mathrm{NDVI}_{\mathrm{soi}}}{\mathrm{NDVI}_{\mathrm{veg}}-\mathrm{NDVI}_{\mathrm{soi}}} \times 100$,

where $\mathrm{NDVI}_{\text {soi }}$ and $\mathrm{NDVI}_{\text {veg }}$ are respectively the values observed for bare soil (vegetation cover $=0$ ) and for full canopy cover (vegetation cover $=100 \%$ ).

SAVI (Huete, 1988; Stefanov et al., 2001) was developed as a modification of the normalized difference vegetation in- dex to correct for the influence of soil brightness when vegetative cover is low. SAVI can be created from Landsat TM and ETM images using the following band combination:

$\mathrm{SAVI}=\left(\frac{\mathrm{NIR}-\mathrm{Red}}{\mathrm{NIR}+\operatorname{Red}+L}\right) \times(1+L)$.

$L$ is a constant (generally set at 0.5 ) used to compensate for the high soil reflectance values observed in desert areas with sparse vegetation.

NDSI (Khan et al., 2005), shown in the form of Eq. (4), is another effective method for extracting salinized soil information (salt-affected areas) in degraded lands that are mostly distributed in the arid ecotones.

$\mathrm{NDSI}=\frac{\mathrm{Red}-\mathrm{NIR}}{\operatorname{Red}+\mathrm{NIR}}$

\subsection{Land cover classification}

In this study, a multistage supervised classification method (MSC) was employed to classify individual images independently, using the maximum likelihood classifier (MLC) (Richards and Jia, 1999). It was integrated with the vegetation and soil indexes to avoid the misclassification due to similar spectral reflectance of different land cover types in standard supervised classification with MLC. The MLC has been the most popular pixel-based classifier used for remote sensing data classification (Foody et al., 1992; Jia et al. 2011), in which the unknown pixel is considered to belong to the class with the maximum probability of membership. The MLC requires sufficient number of representative training sets to produce satisfactory classification results (Hubert-Moy et al., 2001; Chen et al., 2004). For the pixel-based classification, the number of training pixels for each class may be kept as 30 times the number of bands under consideration (Mather, 1999), while Campbell (2006) suggests using at least 100 training pixels per class. With the assistance of a reference map, high-resolution images and vegetation/soil indexes for ground truthing, an interpretation key that describes the spectral attributes for each land cover type was developed and carefully evaluated. When the definition of representative training areas is known, selecting training sites on the image of false-color composite 43-2 (FCC) has the advantage of easily visually distinguishing the classes, and hence ground data collection requirements can be reduced. A total of 200 training sample plots (over 3500 pixels) in which each land cover type had at least 15-30 polygons were selected first in the image of the year 2008 using the "Region of Interest" (ROI) tools provided by ENVI 4.7 software. The same vector layer was then overlaid upon the 1990 and 2000 data sets, and the polygons were modified wherever changes were found. In the process of classification, a training area was given to each of the land cover classes, based on the reflectance signature of different features for the FCC image. The seven land cover types 
Table 1. Description of major land cover types defined in this study.

\begin{tabular}{|c|c|}
\hline Classes name & Description \\
\hline \multirow[t]{4}{*}{ Oasis } & $\begin{array}{l}\text { Agricultural land including cultivated areas with dense annual crops or } \\
\text { vegetables and areas with crop residues or bare soils }\end{array}$ \\
\hline & $\begin{array}{l}\text { Urban or built-up areas including various buildings and open } \\
\text { transportation facilities }\end{array}$ \\
\hline & Forest including trees, shrubs, orchards and shelter forests \\
\hline & $\begin{array}{l}\text { High-coverage grass-/shrubland with vegetation cover of }>50 \% \text {, which } \\
\text { is generally distributedin areas around the artificial oasis with good wa- } \\
\text { ter availability and has a good growth status. } \\
\text { Medium-coverage grass-/shrubland with vegetation cover of } 20-50 \% \text {, } \\
\text { which isalways distributed in areas along high-coverage grass- } \\
\text { /shrubland with water shortages }\end{array}$ \\
\hline Ecotone & $\begin{array}{l}\text { Transitional zone between the desert and oasis with } 5-20 \% \text { vegetation } \\
\text { cover of low desert shrubs with sparse grasses, which experienced } \\
\text { severe water shortages and produced poor grazing conditions }\end{array}$ \\
\hline Water & Open water including lakes, rivers, streams, reservoirs and wetland \\
\hline Desert & $\begin{array}{l}\text { Saline, alkaline land and sandy land with vegetation cover of }<5 \% \text {, } \\
\text { barren rock, Gobi Desert }\end{array}$ \\
\hline
\end{tabular}

were defined for this classification, i.e., agricultural land, urban, forest, medium- and high-coverage grass-/shrubland, low-coverage grass-/shrubland and desert. However, due to the difficulty in separating some land cover classes that have similar spectral characteristics (particularly agricultural land without crops from desert, and medium/high-coverage grass-/shrubland from low-coverage grass-/shrubland), only the six land cover types that have the highest accuracy of identification were included in the initial classification, i.e., agricultural land, urban, forest, water, grass-/shrubland and bare land. Therefore, re-classification of confused land cover classes (grass-/shrubland and bare land) from the initial classification was conducted to extract medium/high- and lowcoverage grass-/shrubland and desert. This was conducted in three stages: firstly, all land cover classes were masked out from the multi-spectral Landsat images, leaving only bare land and thresholding bare-land-based SAVI to unmix the desert from bare soil in agricultural land due to its sensitivity to soil brightness. The SAVI output values range from 0 to 1: values near 0 represent agricultural soil, and values near 1 represent desert. The extracted bare agricultural soil was then merged into the agricultural land. Secondly, all land cover classes were masked from the multi-spectral Landsat images, leaving only the grass-/shrubland and using thresholding based on the fractional vegetation coverage and recoding to medium-, high- and low-coverage grass-/shrubland. Fractional vegetation cover is the most common measurement used for measuring vegetation cover. It ranges from values of 0 to 1 . Lower values represent low-density vegetation (5-20\%), while higher values represent medium- (>20 and $\leqq 50 \%)$ or high-coverage vegetation $(>50 \%)$. The area with vegetation cover of $<5 \%$ are recorded as desert. Finally, by stacking the output of the stages above a final land cover type, classification of the study area was obtained.

After a preliminary classification, some land cover types were merged into one major land cover category to minimize the potential errors of classification and mainly analyze alternative changes between the major landscape types (oasis, desert and ecotone). The classified images were further smoothed using a majority filter with $3 \times 3$ pixel moving window to remove isolated pixels due to spectral mixing. Manual editing (refinement) was then used to modify the classification image based on the prior knowledge about the study area (i.e., the deep shadows of the sand dunes incorrectly classified as water were corrected into the desert). Consequently, four main land cover categories - including "oasis", "ecotone", "desert" and "water" - were used in the final land cover classification, which simplified the analysis of trajectory changes in main land cover types in this study. Oasis was described as the major area where human activities concentrated, including built-up area, agricultural land, forest, high-coverage grass-/shrubland and medium-coverage grass/shrubland. The transitional zone between oasis and desert with sparse vegetation cover of 5-20\%, where natural semishrubs mixed with grasses experienced severe water shortages and poor grazing conditions, was defined as ecotone due to its high probability to alternatively change between the desert and the oasis. The classified land cover types were exported to ArcGIS 9.2, and land cover maps were prepared for the years 1990, 2000 and 2008. Description of major land 
cover types in this classification, as well as the initial land cover classes into which they are grouped, were described in Table 1.

\subsection{Accuracy assessment}

To evaluate the land cover classification performance, the classification accuracy assessment was conducted for each classification by means of the confusion (error) matrix method (Congalton and Green, 1993). Validations of the classification results were accomplished based on a stratified random sampling approach for selection of testing samples from reference data. The additional test samples were selected for the older Landsat images to validate the classification accuracy due to spectral differences for the year 1990, whereas 1999 and 2008 were more or less similar. Thus, a total of 291, 245 and 166 independent test sample plots were generated for land cover maps of 1990, 2000 and 2008, respectively, and transferred to GIS. They were then overlaid with the classified images as well as the suitable (close date) reference maps and high-resolution images for examining the classification performance. In this study, high-resolution IKONOS and QuickBird images were used as the source of the reference data to assess the results of the 2000 and 2008 ETM classifications. For the 1990 TM data, the digitized and georeferenced topographic map and land use map of Xinjiang in 1990 were used for ground verification of testing samples. Because of the difficulty of collecting simultaneous groundtruthing data for historical images, the recent available highresolution image can be used for the comparison in further validation of the classification accuracy (Zhou et al., 2008). By this means, obvious changes in land cover could be reliably detected by image interpretation. In this study, due to the "time gap" between the acquisition dates of the reference data and Landsat images in 1990 TM and 2000 ETM, the Quickbird image in 2008 was used as the basis of the other historical images for comparison and proper interpretation. Producer's accuracy (a measure of omission error) and user's accuracy (a measure of commission error) for each class, as well as overall accuracy and Cohen's kappa coefficient, were calculated for each classification. The classification accuracies obtained from the multistage supervised classification integrated with various indexes and standard supervised classification without using these indexes were compared to show the superiority of the proposed method in this paper.

\subsection{Detection of land cover change}

A post-classification comparison approach was employed to detect the nature, rate and location of changes from 1990 to 2000 and from 2000 to 2008 within the study area. GIS overlay was applied for analysis of the classification results derived from remote sensing data in order to produce change maps and statistical data about the spatial distribution of different land cover changes and non-change areas. For this the GIS overlay operation was carried out using ArcGIS 9.3 software to obtain conversions between the land cover types. The overlay analysis describes the spatial distribution and attributes of changes in land cover during the different study periods. The cross-tabulated matrices between classifications were generated to quantify the conversions from a particular land cover type to other land cover categories, and the corresponding changes in area were calculated as proposed by Pontius et al. (2004). The change occurrence map of land cover types and the temporal trajectories of land cover changes were also generated based on the three resulting maps in 1990, 2000 and 2008 using GIS. The change occurrence map could help better identify areas with high probabilities of change and the human impacts causing such changes within the whole study period (Zhou et al., 2008). The temporal trajectories of changes among land cover types not only reflect the patterns of land cover types but also help deliver the developing trend of the changes.

The annual change rate and average annual transition probabilities of each land cover class were calculated to interpret and assess the land cover change processes.

The annual rate of change for each land cover class was calculated as (FAO, 1995)

$r=\left(A_{2} / A_{1}\right)^{1 /\left(t_{2}-t_{1}\right)}-1$,

where $r$ is the annual change rate, and $A_{2}$ and $A_{1}$ are the land cover class areas at time $t_{2}$ and $t_{1}$, respectively.

The average annual transition probabilities (Mertens and Lambin, 2000) between the ecotone and the other land cover types were computed as

$$
p_{i j}=\frac{a_{i j}}{N} / \sum_{j} a_{i j}
$$

where $a_{i j}$ is the area of land cover $i$ at the initial period that was converted to land cover $j$ at the subsequent period, and $N$ is the number of years of the observed study period.

\section{Results}

\subsection{Land cover changes: integrated methodology of remote sensing and geographic information system}

\subsubsection{Land cover classification}

For each date, four main land cover classes (oasis, ecotone, desert and water) were examined in the Hotan Oasis of arid desert landscape of northwest China. The use of NDVI, SAVI and NDSI data derived from spectral images significantly improved the classification accuracy for the present data set compared to using spectral data (TM or ETM) only. Accuracies were in the range of 91.73-93.82 for using only spectral data as input and reached about $95.96-98.65 \%$ when these indexes were included. The land cover classification results and the percentage of land cover class areas for the 
Table 2. Accuracies of land cover classifications derived from different classification methods (\%).

\begin{tabular}{|c|c|c|c|c|c|c|c|c|c|c|c|c|}
\hline \multirow{3}{*}{$\begin{array}{l}\text { Land cover } \\
\text { type }\end{array}$} & \multicolumn{4}{|c|}{1990} & \multicolumn{4}{|c|}{2000} & \multicolumn{4}{|c|}{2008} \\
\hline & \multicolumn{2}{|c|}{ SC-MLC } & \multicolumn{2}{|c|}{ MSC-MLC } & \multicolumn{2}{|c|}{ SC-MLC } & \multicolumn{2}{|c|}{ MSC-MLC } & \multicolumn{2}{|c|}{ SC-MLC } & \multicolumn{2}{|c|}{ MSC-MLC } \\
\hline & PA & UA & PA & UA & PA & UA & PA & UA & PA & UA & PA & UA \\
\hline Oasis & 95.54 & 91.57 & 98.65 & 95.31 & 91.77 & 93.62 & 100.00 & 97.89 & 93.96 & 94.41 & 96.37 & 99.93 \\
\hline Ecotone & 89.39 & 86.75 & 97.47 & 88.17 & 86.37 & 82.79 & 86.47 & 91.46 & 93.40 & 86.49 & 100.00 & 88.19 \\
\hline Desert & 89.66 & 87.91 & 95.01 & 99.74 & 91.81 & 93.31 & 97.00 & 95.11 & 94.83 & 96.11 & 98.72 & 100.00 \\
\hline Water & 82.52 & 77.54 & 97.75 & 85.00 & 95.25 & 93.48 & 98.00 & 99.38 & 91.96 & 95.02 & 99.93 & 100.00 \\
\hline $\mathrm{OA}$ & \multicolumn{2}{|c|}{91.73} & \multicolumn{2}{|c|}{95.99} & \multicolumn{2}{|c|}{91.82} & \multicolumn{2}{|c|}{95.96} & \multicolumn{2}{|c|}{93.82} & \multicolumn{2}{|c|}{98.65} \\
\hline OK & \multicolumn{2}{|c|}{88.71} & \multicolumn{2}{|c|}{92.36} & \multicolumn{2}{|c|}{89.69} & \multicolumn{2}{|c|}{94.17} & \multicolumn{2}{|c|}{91.53} & \multicolumn{2}{|c|}{97.83} \\
\hline
\end{tabular}

SC-MLC: supervised classification with MLC; MSC-MLC: multistage supervised classification with MLC; OA: overall accuracy; OK: overall kappa; PA: producer's accuracy; UA: user's accuracy.

Table 3. Amounts of changes by land cover classification during 1990-2008 (ha).

\begin{tabular}{lrrrrrr}
\hline Land cover types & 1990 & 2000 & 2008 & $1990-2000$ & $2000-2008$ & $1990-2008$ \\
\hline Oasis & 231635 & 256041 & 313079 & +24406 & +57038 & +81444 \\
Ecotone & 156392 & 116634 & 106553 & -39758 & -10081 & -49839 \\
Desert & 838104 & 866506 & 808535 & +28402 & -57971 & -29569 \\
Water & 47579 & 34529 & 45543 & -13050 & +11014 & -2036 \\
\hline
\end{tabular}

1990, 2000 and 2008 images are shown in Fig. 2. The incorporation of the index data into the classification process showed pronounced increase in Kappa coefficients for the three sets of classified images, which achieved 92.36, 94.17 and 97.83 , while they were only $88.71,89.69$ and 91.53 , respectively, using the original data only without using these indexes (shown in Table 2), which can perfectly meet the demand for land cover change detection in this study. The classification results show that desert was the dominant land cover type within the study area over the whole study period. The next-dominant land cover type was the oasis surrounded by sparsely vegetated ecotone and deserts. It can be found that more than half of the study area was covered by sandy desert in proportion to other land cover types. Table 3 shows the quantitative results of the land cover classification and explains the area coverage for each land cover class by hectare across the three dates.

\subsubsection{Land cover change}

The results show that all land cover types changed during the whole study period. Figure 3 shows the spatial distribution of thematic land cover changes for the two different periods, and Table 3 shows the amounts of area changes in the land cover types during 1990-2000, 2000-2008 and 1990-2008. Overall, desert declined at an annual rate of $-0.2 \%$, from $65.8 \%$ of the study area in 1990 to $63.48 \%$ in 2008. Desert-oasis ecotone showed the largest decline in relation to its area, with only about $68 \%$ of its extent in 1990 remaining in 2008 , and an annual decline of $-2.11 \%$. The amount of water areas declined slightly at an annual rate of $-0.24 \%$, with around $95.7 \%$ of the 1990 extent remaining in 2008. However, oasis experienced an overall expansion during $1990-2008$, which increased annually by $1.7 \%$ and expanded to $135 \%$ of the area occupied in 1990 . The ecotone and desert mainly contributed to the extended oasis, forming an artificial oasis.

Tables 4 and 5 show the cross-tabulation change matrix for the areas changed from one land cover class to another and their percentage comparison to total area during 1990-2000 and 2000-2008. Between 1990 and 2000, the oasis and desert had significant gains while the desert-oasis ecotone and water experienced strong losses. However, the oasis and water areas spread sharply from 2000 to 2008, while there was shrinkage in the areas of ecotone and desert. In the first period, about $2.8 \%$ of the oasis was converted to ecotone while about $14 \%$ of ecotone was developed to oasis. In addition, around $25 \%$ of ecotone was transformed to desert. There was shrinkage in the water area from 1990 to 2000 mainly by changing (about 29.8 and $15.4 \%$ of its area, respectively) to oasis and desert. During the period of 1990-2000, areas of no change represented about $90.7 \%$, and the changed area represented $9.3 \%$. During the second period, about $5.5 \%$ of the oasis was changed to water due to the construction of an artificial reservoirs and ponds. Significant changes also occurred in ecotone, and $44.9 \%$ of its area was converted to oasis. During the same period, a total of $6.2 \%$ of desert area was altered to ecotone due to land reclamation practices in the desert regions. About 17.9 and $12.8 \%$ of water areas were altered to oasis and desert, although it generally showed 
Table 4. The conversion (change) matrix of land cover change from 1990 to 2000*.

\begin{tabular}{llrrrrr}
\hline \multirow{2}{*}{2000} & \multicolumn{6}{c}{1990} \\
\cline { 2 - 7 } Oasis & & Oasis & Ecotone & Desert & Water & Total (2000) \\
& (ha) & $\mathbf{2 1 7 8 1 2}$ & 21968 & 2064 & 14197 & 256041 \\
Ecotone & $($ ha) & $\mathbf{9 4 . 0 3}$ & 14.05 & 0.25 & 29.84 & 20.10 \\
& $(\%)$ & 2.79 & $\mathbf{6 0 . 1 1}$ & 1.18 & 2.36 & 116634 \\
Desert & $($ ha) & 1122 & 39031 & $\mathbf{8 1 9 0 4 5}$ & 7308 & 866506 \\
\multirow{3}{*}{ Water } & $(\%)$ & 0.48 & 24.96 & $\mathbf{9 7 . 7 3}$ & 15.36 & 68.03 \\
& $($ ha) & 6236 & 1393 & 1951 & $\mathbf{2 4 9 4 9}$ & 34529 \\
\multirow{3}{*}{ Total (1990) } & $(\%)$ & 2.69 & 0.89 & 0.15 & $\mathbf{5 2 . 4 4}$ & 2.71 \\
& $($ ha) & 231635 & 156392 & 838104 & 47579 & 1273710 \\
& $(\%)$ & 100.00 & 100.00 & 100.00 & 100.00 & 100.00 \\
\hline
\end{tabular}

* The numbers on the diagonal that are colored in bold represent the unchanged area of the land cover types, while others represent the areas changed to other land cover types.

Table 5. The conversion (change) matrix of land cover change from 2000 to $2008^{*}$.

\begin{tabular}{llrrrrr}
\hline \multirow{2}{*}{2008} & \multicolumn{7}{c}{2000} \\
\cline { 2 - 7 } Oasis & Oasis & Ecotone & Desert & Water & Total (2008) \\
& (h) & $\mathbf{2 4 0 7 0 3}$ & 52438 & 13744 & 6194 & 313079 \\
Ecotone & (ha) & $\mathbf{9 4 . 0 1}$ & 44.96 & 1.59 & 17.94 & 24.58 \\
& $(\%)$ & 0.06 & $\mathbf{5 2 6 4 6}$ & 53720 & 31 & 106553 \\
Desert & $($ ha) & 1223 & 9635 & $\mathbf{7 9 3 2 6 2}$ & 4415 & 808535 \\
& $(\%)$ & 0.48 & 8.26 & $\mathbf{9 1 . 5 5}$ & 12.79 & 63.48 \\
Water & (ha) & 13959 & 1915 & 5780 & $\mathbf{2 3 8 8 9}$ & 45543 \\
\multirow{2}{*}{ Total (2000) } & $(\%)$ & 5.45 & 1.64 & 0.67 & $\mathbf{6 9 . 1 9}$ & 3.58 \\
& $(\%)$ & 256041 & 116634 & 866506 & 34529 & 1273710 \\
& 100.00 & 100.00 & 100.00 & 100.00 & 100.00 \\
\hline
\end{tabular}

* The numbers on the diagonal that are in bold represent the unchanged area of the land cover types, while others represent the areas changed to other land cover types.

an increase in this period. Thus, from 2000 to 2008 the unchanged and changed areas represented 87.2 and $12.8 \%$, respectively.

Land cover changes did not occur at equal rates during the two time intervals. Between 1990 and 2000, ecotone experienced a strong loss at an annual rate of $-2.93 \%$. This annual rate declined to $-1.13 \%$ for the $2000-2008$ period. Overall, ecotone losses during the two study periods were offset by about one-third by ecotone gains. During the period of highest ecotone loss (1990-2000), oasis and desert cover increased at annual rate of 0.34 and $1 \%$, respectively. However, the desert decreased at annual rate of $-0.87 \%$ from 2000 to 2008 , while oasis continued increasing at an annual rate of $2.51 \%$. The area of water decreased at annual rate of $-3.2 \%$ during the 1990-2000 period but increased at annual rate of $3.46 \%$ during the $2000-2008$ period. Thus, the total changes occurred in water areas coincided with the trends of increasing water demands for the oasis expansion.

\subsubsection{Land cover change patterns}

From Table 6 it can be shown that the ecotone continued to shrink throughout the two study periods. The average annual transition probability from ecotone to oasis increased by $6.72 \%$, while the annual transition probability from desert to ecotone increased by $5.81 \%$. Thus, the ecotone loss was partly offset by the newly developed oasis along the outer edges of the ecotone.

The spatial distribution of the intensity of land cover changes is shown in Fig. 4. The change frequency among the land cover types indicated the areas where human activities are more intense. It was found that $12.97 \%$ of the study area was subject to only one change, $3.76 \%$ was subject to two changes and $83.27 \%$ remained unchanged during the entire study period. The land cover changes mostly have occurred at the fringe of the oasis in the northwest and northeast, and in the north along the Yorungkash and Karakash rivers, as these areas were clear priorities for urban and agricultural 
Table 6. The average annual transition probabilities between ecotone and other land cover types (units: \%).

\begin{tabular}{lrrrrrrrr}
\hline & \multicolumn{3}{c}{$1990-2000$} & & \multicolumn{3}{c}{$2000-2008$} \\
\cline { 2 - 3 } \cline { 7 - 9 } & Oasis & Desert & Water & & Oasis & Desert & Water \\
\hline From ecotone to other land cover types & 3.52 & 6.26 & 0.22 & & 10.24 & 1.88 & 0.37 \\
From other land cover types to ecotone & 2.86 & 6.65 & & 0.50 & & 0.04 & 12.46 & 0.007 \\
\hline
\end{tabular}
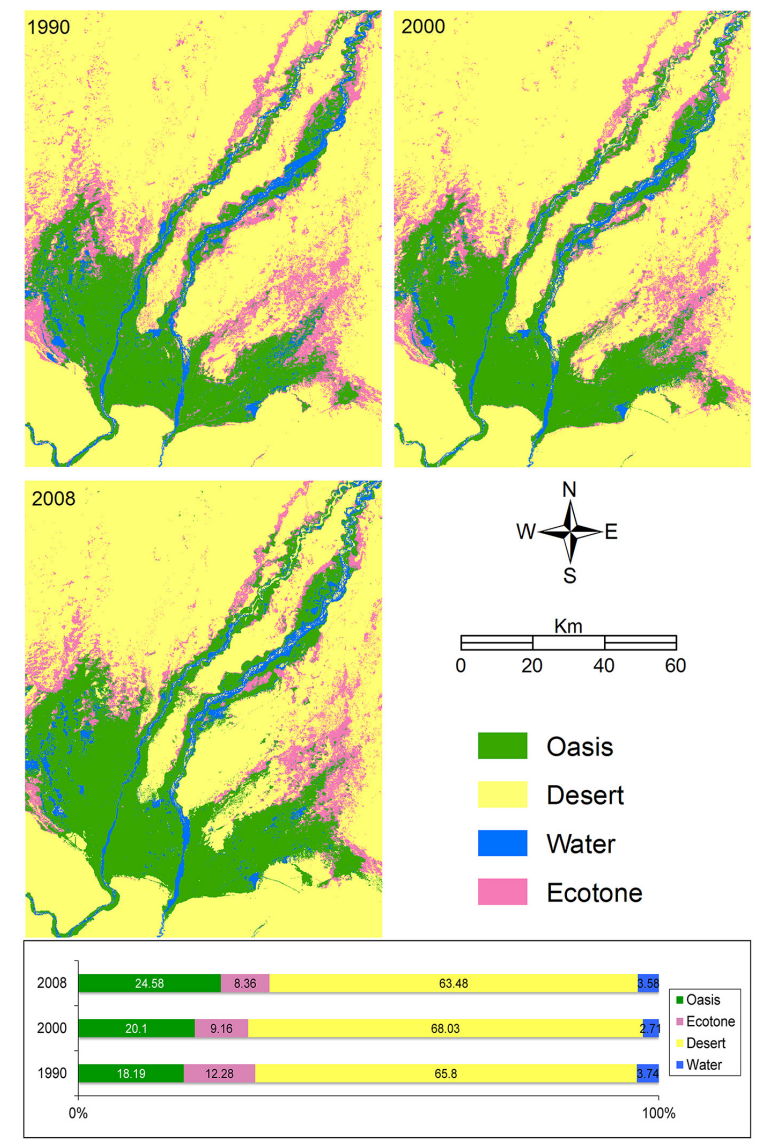

Figure 2. Land cover maps of the Hotan Oasis for the years 1990, 2000 and 2008 and the respective extents of land cover classes by percentage (study area: 1273710 ha).

developments. The temporal trajectory of land cover changes explained the patterns and trends of land cover changes in the Hotan Oasis (Fig. 5). It can be found that the major contributions to net change were the conversion of ecotone to oasis and desert during 1990-2000, while the major changes were the conversions of ecotone to oasis and desert to ecotone between 2000 and 2008.

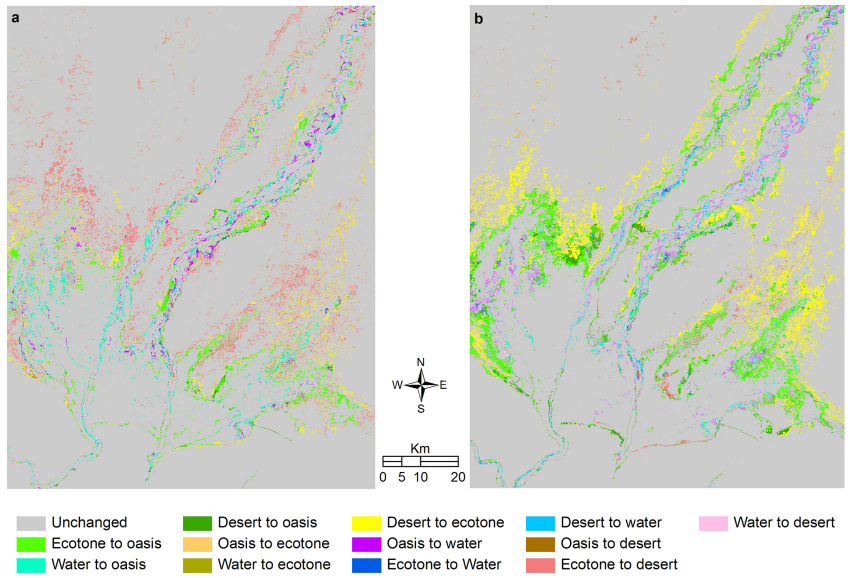

Figure 3. Land cover change maps of the Hotan Oasis during (a) 1990-2000 (total unchanged area: $1155806 \mathrm{ha}$; total changed area: 117904 ha; ecotone to oasis: 21968 ha; water to oasis: $14197 \mathrm{ha}$; desert to oasis: 2064 ha; oasis to ecotone: 6465 ha; water to ecotone: $1125 \mathrm{ha}$; desert to ecotone: 15044 ha; oasis to water: $6236 \mathrm{ha}$; ecotone to water: 1393 ha; desert to water: 1951 ha; oasis to desert: $1122 \mathrm{ha}$; ecotone to desert: $39031 \mathrm{ha}$; water to desert: $7308 \mathrm{ha}$ and (b) 2000-2008 (unchanged area: 1110500 ha; changed area: 163210 ha; ecotone to oasis: 52438 ha; water to oasis: $6194 \mathrm{ha}$; desert to oasis: 13744 ha; oasis to ecotone: 156 ha; water to ecotone: 31 ha; desert to ecotone: 53720 ha; oasis to water: 13959 ha; ecotone to water: 1915 ha; desert to water: 5780 ha; oasis to desert: 1223 ha; ecotone to desert: 9635 ha; water to desert: 4415 ha).

\subsection{Driving forces: implications for arid oasis landscape planning and management}

\subsubsection{Natural forces}

The influence of climate variability on land cover changes seems to be significant for the Hotan Oasis' evolution. In the arid desert oasis of Hotan, the main natural factors - such as runoff, annual mean temperature, annual mean precipitation and the amount of water consumption in the oasis - were collected from the hydrological and meteorological observation station located in the study area. The observed hydrological and meteorological data plotted in Fig. 6a and b showed that during the last few decades the mean annual temperature and precipitation in the Hotan Oasis had an increasing trend, whereas the average annual runoff of the Hotan River showed 

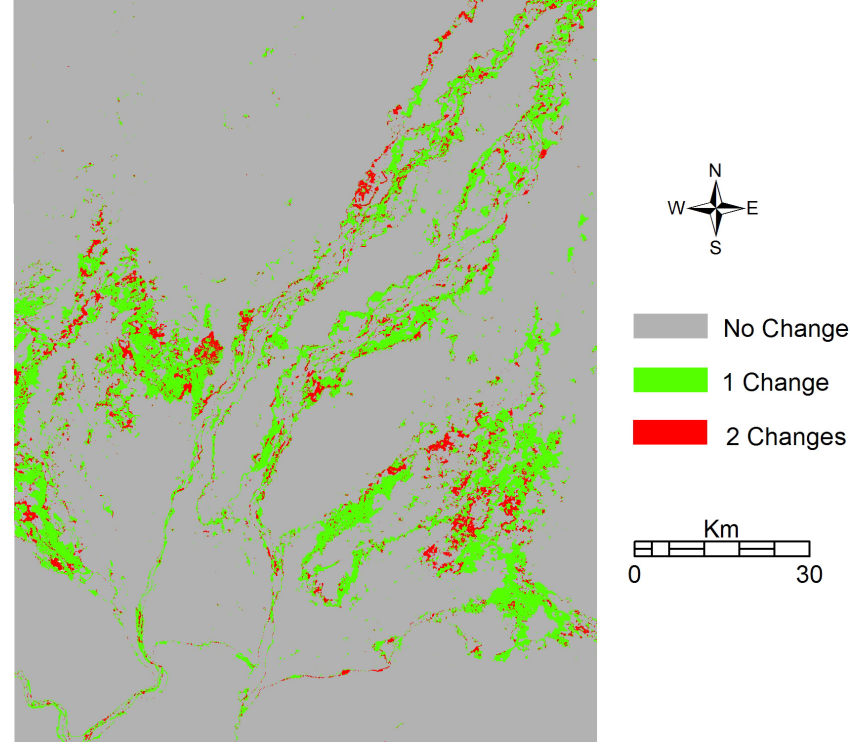

Figure 4. Distribution of areas showing change occurrence among land cover types across the two periods from 1990 to 2008.

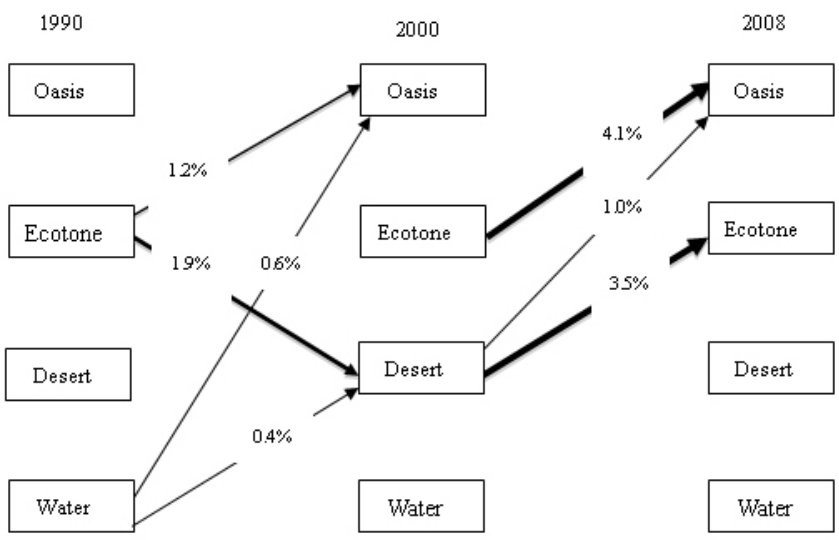

Figure 5. Major change trajectories and their contributions to net change in percentage of the study area (thick lines correspond to net change $>3.5 \%$, intermediate lines correspond to net changes between 1.8 and $3.5 \%$ and thin lines correspond to net change $<1.8 \%$; only net contributions to change $>5000$ ha, or $0.4 \%$ of the study area, are represented).

decreasing tendency (Fig. 6c) due to its main recharging source from glacial melt water in the Kunlun Mountains area.

\subsubsection{Human forces}

\section{Population growth}

The rapid migration of cultivators and herders into the marginal sites of the Hotan Oasis resulted in rising population densities. In 1990, a total of 0.85 million people lived in the Hotan Oasis; in 2000 the population was 1.07 million. During the intervening 10 years, population increased
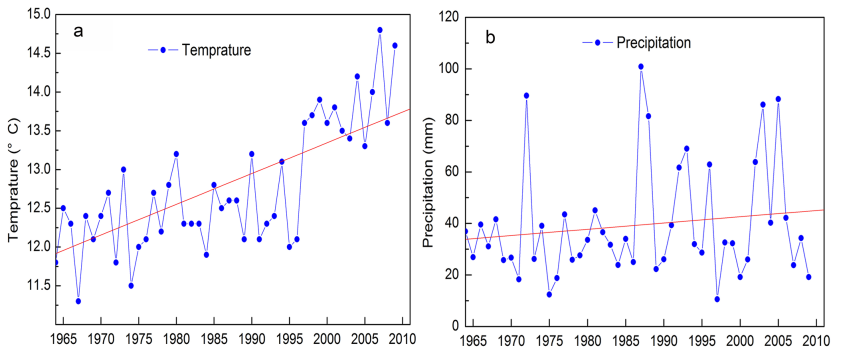

Year
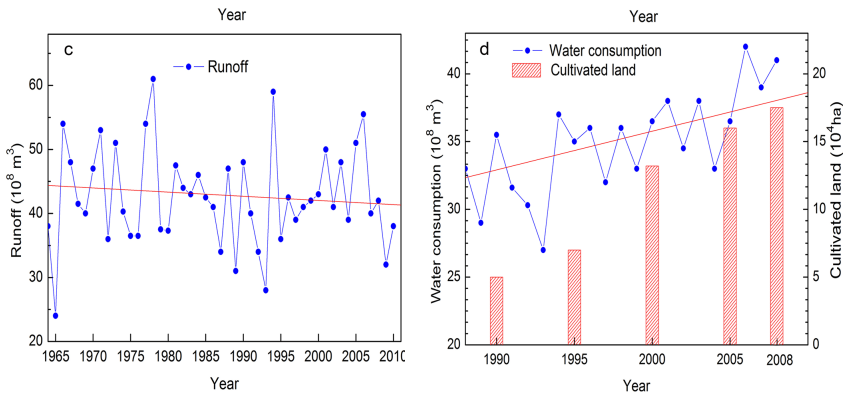

Figure 6. Average annual temperature (a) and precipitation (b) in the Hotan Oasis. Runoff of Hotan River (c), water consumption and area change of cultivated land in the Hotan Oasis (d).

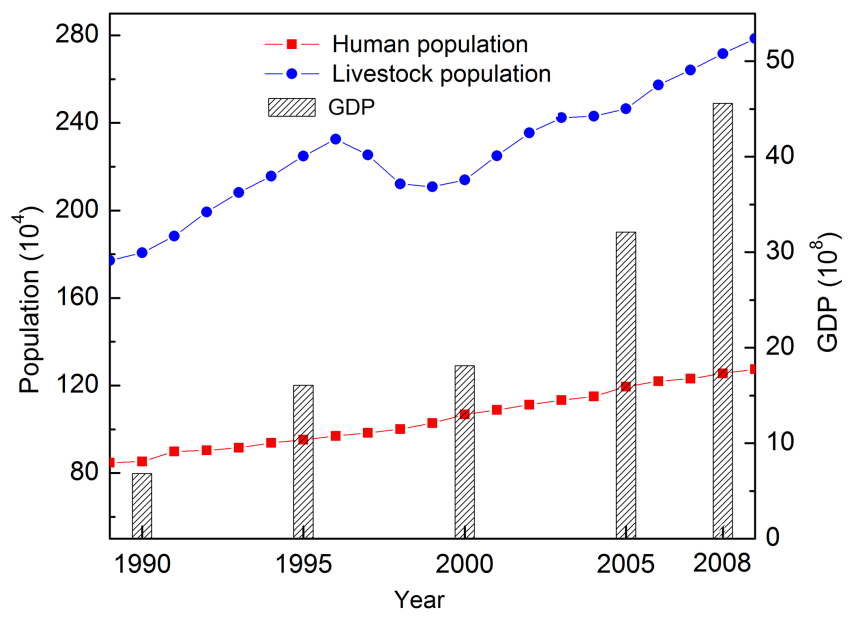

Figure 7. Population, livestock and GDP in the Hotan Oasis.

by 0.22 million people with a growth rate of $20.15 \%$. In 2008 , the total population of the Hotan Oasis reached up to 1.25 million. It increased by $17.5 \%$ compared with 1990 , and the growth rate was $14.9 \%$ (Fig. 7). Along with the increasing population, arable land increases to meet food consumption. Accordingly, a significant proportion of grasslands and paddy fields in the study area are lost to other uses (e.g., residential areas, farmland and other traditional industries). Therefore, population growth, as the comprehensive reflection of the environmental capacity, is the main human factor affecting land use in the Hotan Oasis. 


\section{Economic development}

The reform of economic structure and transition to the market economy played a significant role in land cover changes of the Hotan Oasis. The economic growth based on the agricultural and industrial production has accelerated since 1990. From Fig. 7 it can be found that the GDP of Hotan was only 683 million CNY in 1990, which increased to 1812 million CNY in 2000 and 4960 million CNY in 2008 at an annual increasing rate of 16.5 and $21.7 \%$ during the two study periods. The cultivated land in the Hotan Oasis expanded from 50000 ha in 1990 to 130000 ha in 2000 with an annual increasing rate of $16 \%$ (Fig. 6d). Large areas of plantation of economic crops, such as cotton, were conducted in the region, which greatly influenced the actual water consumption and reallocated water resources by changing areas and structures of crop plantation. Thus, the volume of water consumption had a sharp increase in the Hotan Oasis during the whole study period (Fig. 6d).

Responding to a wide range of land degradation, the "Conversion of Cropland to Forest and Grassland Program (CCFGP)" was initiated in 1999 in many dryland oases of northwest China to minimize soil erosion and vegetation degradation, as well as to improve utilization of water resources. Thus, the area of cultivated land was 175000 ha in 2008 , and the annual increasing rate decreased to $4.3 \%$ during 2000-2008 (Fig. 6d). Unsustainable land use - such as overexploitation of surface and groundwater, land abandonment and overgrazing - was then accompanied by the rapid economic growth in the Hotan Oasis. For example, the livestock population of grazing animals in the Hotan Oasis increased from 1737200 in 1990 to 2573200 in 2008, which was far beyond the carrying capacity (Fig. 7).

\section{Sociocultural factors}

The prefecture of Hotan was a crucial hub in the ancient Silk Road, where the combination of the community economy and the unique culture was prominent. Traditional agriculture, animal husbandry and various types of agro-forestry in the oasis, as the basis of subsistence, provide different goods and services. The economic activities centered on cultural industries, such as fruit farming and Uyghur medicine, contributed to the development of the economy in the oasis. The cultural ecosystem services of aesthetics had a rising trend in the Hotan Oasis (increased about $0.58 \times 10^{8}$ Yuan ha $^{-1}$ ) during the period of 1990-2008 (Yang et al., 2013). However, these resource-processing practices and the traditional beliefs of the local farmers always influence the decisions on land use.

\section{Discussion}

The low classification accuracies and misclassifications among grass-/shrublands of different vegetation coverage, as well as bare agriculturally used land and desert, can be explained by their similar reflectance characteristics. The multistage supervised classification method by masking out the spectrally identifiable classes and then differentiating the mixed (confused) classes with incorporation of vegetation and soil indexes as an additional step showed positive effects on the classification of land cover types. As Table 2 shows, the results from this method provide much better classification accuracy than those from MLC without using these indexes, in which overall classification accuracy increased by roughly $4-5 \%$. For example, the NDSI allows the detection of salt-affected soils and areas potentially at risk of salinization in the degraded lands, which are mostly distributed in the marginal sites around the oasis (Yu et al., 2010). However, this is time-consuming, particularly on a broader scale. Merging some initial land cover types (agricultural land, forest, high-coverage grass-/shrubland, mediumcoverage grass-/shrubland and built-up area) into the oasis facilitated the analysis of the alternative changes and general trends of the desert-oasis ecotone. Nevertheless, the results clearly stress the importance of well-defined land cover classes for image classification. Class definition of land cover also needs to consider typical surface characteristics rather than spectral properties only, e.g., for the ecotone class in the present study. The understanding of what kind of land cover classes can be discriminated by what kind of spectral, topographic or temporal information is, however, still rudimentary, and further research on the separability of specific land cover classes is required to advance image classification.

During classification accuracy assessment, due the difficulty of collecting simultaneous ground-truthing data, only the Quickbird image was synchronous with the 2008 ETM data; however, the Landsat image of 2000 was recorded 1 month later, and thus more agricultural land was already harvested compared to the reference image (IKONOS) of 2000. As a result, the Quickbird image of the year 2008 was used as the basis of the other two historical images for comparison and proper interpretation. By this means, obvious land cover changes such as oasis to water and oasis to desert could be reliably detected by image interpretation. For a more precise evaluation of the classification accuracies, the high-resolution imagery taken on the same or closer dates integrating field investigations during different vegetation periods would reveal better results.

Overall, the trends of land cover change in desert oasis of the present study were largely similar as compared to steppe and desert regions of northern China with oasis expansion (expanding urban areas as well as farmlands), decreasing area of ecotone rangelands and degraded land due to being desertified by agricultural intensification, wind erosion, water deficiency and overgrazing in the last decades ( $\mathrm{Li}$ et al., 2004b; Luo et al., 2008; Hao and Ren, 2009; Yu et al., 2010). Although the warmer and wetter climate of the Hotan Oasis (Fig. 6a, b) was favorable to oasis expansion, the high evaporation rate and frequent flooding of Hotan River accelerated 
soil salinization across the basin (Zhao, et al., 2009; Huang and Shen, 2010).

In the arid areas, the socioeconomic factors have been becoming main driving factors of land use/cover changes (Hao et al., 2008). Given the population increase, the economic growth based on the agricultural and industrial production was accelerated. Accordingly, a significant proportion of grasslands and paddy fields in the study area have been lost for other uses (e.g., farmlands). The cultivated land in 2000 in the Hotan Oasis expanded to more than double that in 1990 with plantation of economic crops in large areas. Thus, overintensification of agriculture led to increase in water consumption within the oasis by excessive surface water exploitation and groundwater pumping. The total area of water increased in the Hotan Oasis during 2000-2008 mainly due to construction of artificial reservoir to provide water for human and livestock consumption as well as for supplementary irrigation in the dry season. The productivity of oasis systems is based on irrigation water, while the surrounding ecotone instead depends almost on groundwater (Wang and Cheng, 2000; Hao et al., 2009). The dramatic increase in the use of water in the oasis indicates that the level of the groundwater table and groundwater mineralization increase significantly, causing the higher rate of soil salinization (Hamid et al., 2002; Wang and Li, 2013). Consequently, the natural grass-/shrubland in the desert-oasis ecotone has declined due to less water availability from groundwater. According to the results in the study, the total size of the oasis increased from 231635 to 313079 ha between 1990 and 2008, while desert-oasis ecotone decreased by nearly 49839 ha from 1990 to 2008 . This corresponds to the population growth and economic development of the Hotan Oasis and of Xinjiang in the last decades.

The reduction of agricultural land and expansion of shelter forests and grasses in the oasis since 2000 indicates that the CCFGP is already producing measurable results. This might have contributed to the promotion of the internal stability of the Hotan Oasis to a certain extent. However, the expanding trend of the oasis area still remained unchanged during the period of 2000-2008. Hence, there is an urgent need to consider the fragility of the ecological environment and water scarcity when management improvement is undertaken in the desert oasis. Furthermore, overgrazing due to increasing livestock population was responsible for the constantly decreased area of desert-oasis ecotone during the whole study period. Due to the removal of the grasses and woody plants that protect soils from wind and water erosion because of overgrazing and firewood collection, the soil around the oasis fringe would probably experience further degradation. Therefore, effective effort is needed toward the ecological security in the oasis and protection of natural vegetation in the desert-oasis ecotone.

In addition, the traditional cultural beliefs and lack of education of rural farmers regarding land use regulations influence the decisions on land use in the process of shifting toward the intensive irrigation agriculture and adoption of new agricultural management systems. It is thus necessary to build an adaptive application policy of integrating the useful traditional practices into the new land use and water management systems with a specific focus on raising awareness of local communities concerning the urgency of desertification control in the Hotan River basin.

\section{Conclusions}

In this paper, we have presented research on the spatialtemporal pattern of land cover change in the fragile ecosystem of arid desert oasis in northwest China. Multi-temporal remotely sensed images, including TM and ETM, were used to analyze the land cover change and to identify change trajectories. The natural and human driving forces were examined using hydro-climatic data and socioeconomic data.

Results of this study revealed that the multistage supervised classification method using the MLC, incorporating ancillary data such as vegetation and soil indexes into the classification process, gives more reliable and accurate results overall and on the level of single land cover classes compared to the standard classification method. This indicates the large potential of different ancillary data for increasing classification accuracy in change detection within complex desert oasis systems. The analysis of the temporal changes of land cover and their spatial distribution showed that oasis continued to expand and desert-oasis ecotone kept decreasing, while water and desert were fluctuating over the two study periods due to the accelerated oasification process and desertified land reclamation in the desert-oasis ecotone. The analysis of driving factors indicated that the human-induced changes were still dominating in land cover change processes of the study area, which represent an irreversible impact on the arid environment.

In this study, we extended the concepts and methodology of change detection analysis to the study of an arid environment. Further studies will be focused on the spatiotemporal patterns and relationships between land cover types and local land use practices. Through these studies human activities and their environmental responses, particularly the long-term consequences, will be assessed, so that better, science-based arid-landscape management decisions can be made.

Acknowledgements. This study was funded by one of the National Basic Research Programs of China (grant no. 2014CB954204) and the National Natural Science Foundation of China (grant nos. 41361140361, 41461023). The authors thank the anonymous referees for the supportive and constructive comments that helped to improve the manuscript.

Edited by: A. Cerdà 


\section{References}

Alphan, H.: Classifying land cover conversion in coastal wetlands in the Mediterranean: pairwise comparisons of Landsat images, Land Degrad. Develop., 23, 278-292, 2012.

Bakr, N., Weindorf, D. C., Bahnassy, M. H., Marei, S. M., and ElBadawi, M. M.: Monitoring land cover changes in a newly reclaimed area of Egypt using multi-temporal Lansat data, Appl. Geogr., 30, 592-605, 2010.

Bruun, T. B., Elberling, B., Neergaard, and Magid, J.: Organic carbon dynamics in different soil types after conversion of forest to agriculture, Land Degrad. Develop., doi:10.1002/ldr.2205, 2013.

Campbell, J.: Introduction to Remote Sensing, London: Taylor \& Francis, 2006.

Carlson, T. N. and Ripley, D. A.: On the relation between NDVI, Factional Vegetation Cover, and Leaf Area Index, Remote Sens. Environ., 62, 241-252, 1997.

Chen, D., Stow D. A., and Gong, P.: Examining the effect of spatial resolution and texture window size on classification accuracy: an urban environment case, Int. J. Remote Sens., 25, 2177-2192, 2004.

Chen, X., Vierling, L., and Deering, D.: A simple and effective radiometric correction method to improve landscape change detection across sensors and across time, Remote Sens. Environ., 98, 63-79, 2005.

Chen, Y. and Tang, H.: Desertification in North China: Background, Anthropogenic impacts and Failures in Combating it, Land Degrad. Develop., 16, 367-376, 2005

Cheng, W. M., Zhou, C. H., Liu, H. J., Zhang, Y., Jiang, Y., Zhang, Y. C., and Yao, Y. H.: The oasis expansion and eco-environment change over the last 50 years in Manas River Valley, Xinjiang, Sci. China Ser. D, 49, 163-175, 2006.

Congalton, R. G.: A review of assessing the accuracy of classifications of remotely sensed data, Remote Sens. Environ., 37, 3 5-47, 1991.

Congalton, R. G. and Green, K.: A practical look at the sources of confusion in error matrix generation, Photogramm. Engin. Remote Sens., 59, 641-644, 1993.

Coppin, P., Jonckheere, I., Nackaerts, K., Muys, B., and Lambin, E.: Digital change detection methods in ecosystem monitoring: a review, Int. J. Remote Sens., 25, 1565-1596, 2004.

Dickenson, R.: Land processes in climate models, Remote Sens. Environ., 51, 27-38, 1995.

Ding, J. L., Zhang, Y., and Tiyip, T.: Study on the Change of SpatialTemporal LUCC in Desert-Oasis Ecotone, Res. Environ. Sci., 19, 100-105, 2006

Dittrich, A., Buerkert, A., and Brinkmann, K.: Assessment of land use and land cover changes during the last 50 years in oases and surrounding rangelands of Xinjiang, NW China, J. Agr. Rural Develop. Trop. Subtrop., 111, 129-142, 2010.

FAO: Forest resources assessment, 1990: Global Synthesis, FAO Forestry Paper 124, FAO, Rome, 1995.

FAO: World reference base for soil resources: A framework for international classification, correlation and communication, World soil resources reports, 103, FAO, Rome, 2006.

Foody, G. M., Campbell, N. A., Trodd, N. M., and Wood, T. F.: Derivation and applications of probabilistic measures of class membership from the maximum-likelihood classification, Photogramm. Engin. Remote Sens., 58, 1335-1341, 1992.
Geist, H. J. and Lambin, E. F.: Proximate causes and underlying driving forces of tropical deforestation, BioScience, 52, 143-150, 2002.

Gui, D. W., Mu, G. J., Lei, J. Q., Zeng, F. J., and Wang, H.: Assessment of farmland soil quality under different utilization intensity in arid area, Chin. J. Appl. Ecol., 20, 894-900, 2009.

Hamid, Y., Pan, X. L., Taxpolat, T., Ernst, G., and Zhang, F.: Water resource development in the Tarim Basin and its ecoenvironmental effects, Resour. Sci., 24, 48-54, 2002.

Han, D. L. and Meng, X. Y.: Recent Progress of Research on Oasis in China, Chin. Geogr. Sci., 9, 199-205, 1999.

Hao, H. and Ren, Z.: Land use/land cover change (LUCC) and eco-environmental response to LUCC in farming-pastoral zone, China, Agr. Sci. China, 8, 91-97, 2009.

Hao, X. M., Chen, Y. N., Xu, C. C., and Li, W. H.: Impacts of climate changes and human activities on the surface runoff in the Tarim river basin over the last fifty years, Water Resour. Manage., 22, 1159-1171, 2008.

Hao, X. M., Li, W. H., Huang, X., Zhu, C. G., and Ma, J. X.: Assessment of the groundwater threshold of desert riparian forest vegetation along the middle and lower reaches of the Tarim River, China, 24, 178-186, 2009.

Hu, R. J., Fan, Z. L., Wang, Y. J., Yang, Q., and Huang, Y. Y.: Assessment about the impact of climate change on environment in Xinjiang since recent 50 years, Arid Land Geogr., 24, 97-103, 2001.

Huang, L. M. and Shen, B.: Impacts of human activities on river flow regime in Arid Zones - A case study of Hotan river basin, China Water Resources and Hydropower Press, Beijing, China, 2010.

Huang, L. M., Wu, L. N., and Shen, B.: Quantitative Estimation of Annual Runoff Variation from Hotan River, China, J. Sustain. Develop., 2, 120-124, 2009.

Hubert-Moy, L., Cotonnec, A., Du, L., Chardin, A., and Perez, P.: A comparison of parametric classification procedures of remotely sensed data applied on different landscape units, Remote Sens. Environ., 75, 174-187, 2001.

Huete, A. R.: A soil-adjusted vegetation index (SAVI), Remote Sens. Environ., 25, 295-309, 1988.

Jia, B., Zhang, Z., Ci, L., Ren, Y., Pan, B., and Zhang, Z.: Oasis land-use dynamic and its influence on the oasis environment in Xinjiang, China, J. Arid Environ., 56, 11-26, 2004.

Jia, K., Wu, B. F., Tian, Y. C., Zeng, Y., and Li, Q. Z.: Vegetation classification method with biochemical composition estimated from remote sensing data, Int. J. Remote Sens., 32, 9307-9325, 2011.

John, R., Chen, J. Q., Lu, N., and Wilske, B.: Land cover/land use change in semi-arid Inner Mongolia: 1992-2004, Environ. Res. Lett., 4, 1-9, 2009.

Kalluri, S.: Monitoring Ecosystems Vulnerable to Climate Change, Proceedings International Geoscience and Remote Sensing Symposium (IGARSS'02), Toronto, 2802-2804, 2002.

Khan, M. N., Rastoskuev, V.V., Sato, Y., and Shiozawa, S.: Assesment of hydrosaline land degradation by using a simple approach of remote sensing indicators, Agr. Water Manage., 77, 96-109, 2005.

Lambin, E. F. and Geist, H. J.: Global LU/land-cover changes What have we learned so far?, IGBP Glob. Change Newslet., 46, 27-30, 2001. 
Lambin, E. F., Rounsevell, M. D. A., Geist, H. J.: Are agricultural land-use models able to predict changes in land-use intensity?, Agric Ecosyst Environ, 82, 321-331, 2000.

Lambin, E. F., Geist, H., and Lepers, E.: Dynamics of land use and cover change in tropical regions, Ann. Rev. Environ. Resour., 28, 205-241, 2003.

Lei, J., Luo, G. P., Zhang, X. L., and Lu, Q.: Oasis System and Its Reasonable Development in Sangong River Watershed in North of the Tianshan Mountains, Xinjiang, China, Chin. Geogr. Sci., 16, 236-242, 2006.

Li, Q., Mayzlish, E., Shamir, I., Pen-Mouratov, S., Sternbeerg, M., and Steinberger, Y.: Impact of grazing on soil biota in a Mediterranean grassland, China, Land Degrad. Develop., 16, 581-592, 2005.

Li, X. H. and Tiyip, T.: Extraction of Precautious Line and Analysis on Ecological Environment Change in Oasis Desert Transitional Belt: A case study of Hetian Oasis, Xinjiang, J. Desert Res., 28, 77-82, 2008.

Li, X. Y., Wang, L. X., Zhang, Y. S., and Zhang, H. Q.: Analysis of roles of human activities in land desertification in arid area of Northwest China, Scientia Geographica Sinica, 24, 68-75, 2004a.

Li, Z., Li, X., Wang, Y., Ma, A., and Wang, J.: Land-use change analysis in Yulin prefecture, northwestern China using remote sensing and GIS, Int. J. Remote Sens., 25, 56591-5703, 2004b.

Liu, S., Liu, H., Hu, Y., Zhang, C., Liang, F., and Wang, J.: Numerical simulations of land surface physical processes and land-atmosphere interactions over oasis-desert/Gobi region, Sci. China Ser. D, 50, 290-295, 2007.

Liu, Y. X., Zhang, X. L., Lei, J., and Zhu, L.: Urban expansion of oasis cities between 1990 and 2007 in Xinjiang, China, Int. J. Sustain. Develop. World Ecol., 17, 253-262, 2010.

Lu, D., Mausel, P., Brondiozio, E., and Moran, E.: Change detection techniques, Int. J. Remote Sens., 25, 2365-2407, 2004.

Luo, G. P., Zhou, C. H., Chen, X., and Li, Y.: A methodology of characterizing status and trend of land changes in oasis: A case study of Sangong River watershed, Xinjiang, China, J. Environ. Manage., 88, 775-783, 2008.

Luo, G. P., Feng, Y. X., Zhang, B. P., and Chen, W. M.: Sustainable land-use patterns for arid lands: A case study in the northern slope areas of the Tianshan Mountains, J. Geogr. Sci., 20, 510-524, 2010.

Ma, J. Z., Lai, T. W., and Li, J. J.: The Impact of Human Activities on Groundwater Resources in The South Edge of Tarim Basin, Chin. Georaph. Sci., 12, 50-54, 2000.

Mas, J. F.: Monitoring land-cover changes: a comparison of change destection techniuques, Int. J. Remote Sens., 20, 139-152, 1999.

Masek, J. G., Lindsay, E. F., and Goward, S. N.: Dynamics of urban growth in the Washington DC metropolitan area, 1973-1996, from Landsat observations, Int. J. Remote Sens., 21, 3473-3486, 2000.

Masoud, A. A. and Koike, K.: Arid land salinization detected by remotely-sensed land cover changes: A case study in the Siwa region, NW Egypt, J. Arid Environ., 66, 151-167, 2006.

Mather, P. M.: Computer processing of remotely sensed images: an introduction, 2nd edition, Wiley, Chichester, 1999.

Mertens, B. and Lambin, E. F.: Land-Cover - Change Trajectories in Southern Cameroon, Ann. Assoc. Amer. Geogr., 90, 467-494, 2000 .
Neilson, R. P.: The Transient Ecotone Response to Climatic Change: Some Conceptual and Modelling Approaches, Ecol. Appl., 3, 385-395, 1993.

Pontius, Jr. R. G., Shusas, E., and McEachern, M.: Detecting important categorical land changes while accounting for persistence, Agriculture, Ecos. Environ., 101, 251-268, 2004.

Qi, S., Li, X., and Duan, H.: Oasis land-use change and its environmental impact in Jinta Oasis, arid northwestern China, Environ. Monit. Assess., 134, 313-320, 2007.

Reid, R. S., Kruska, R. L., Muthui, N., Taye, A., Wotton, S., Wilson, C. J., and Mulatu, W.: Land-use and land-cover dynamics in response to changes in climatic, biological and socio-political forces: the case of southwestern Ethiopia, Landscape Ecol., 15, 339-355, 2000.

Reynolds, J. F., Stafford-Smith, D. M., Lambin, E. F., Turner, B. L., Mortimore, M., Simon Batterbury, S. P. J., Downing, T. E., Dowlatabadi, H., Fernández, R. J., Herrick, J. E., HuberSannwald, E., Jiang, H., Leemans, R., Lynam, T., Maestre, F. T., Ayarza, M., Walker, B.: Global Desertification: Building a Science for Dryland Development, Science, 316, 847-851, 2007.

Richards, J. A. and Jia, X.: Remote Sensing Digital Image Analysis: An Introduction (3rd Edn.), Springer-Verlag, Berlin, Germany, p. 363, 1999.

Rouse, J. W., Haas, R. H., Schell, J. A., and Deering, D. W.: Monitoring vegetation systems in the Great Plains with ERTS, In 3rd ERTS Symposium, NASA SP-351 I, 309-317, 1973.

Schulz, J. J., Cayuela, L., Echeverria, C., Sala, J., and Benayas, J. M. R.: Monitoring land cover change of the dry landscape of Central Chile (1975-2008), Appl. Geogr., 30, 436-447, 2010.

Serra, P., Pons, X., and Saurí, D.: Land-cover and land-use change in a Mediterranean landscape: a spatial analysis of driving forces integrating biophysical and human factors, Appl. Geogr., 28, 189-209, 2008.

Shippert, M. M., Walker, D. A., Auerbach, N. A., Auerbach, N. A., and Lewis, B. E.: Biomass and leaf-area index maps derived from SPOT images for Toolik Lake and Imnavait Creek areas, Alaska, Pol. Record, 31, 147-154, 1995.

Song, C., Woodcock, C. E., Seto, K. C., Pax, L. M., and Macomber, S. A.: Classification and change detection using Landsat TM data: when and how to correct atmospheric effects?, Remote Sens. Environ., 75, 230-244, 2001.

Stefanov, W. L., Ramsey, M. S., and Christensen, P. R.: Monitoring urban land cover change: An expert system approach to land cover classification of semiarid to arid urban centers, Remote Sens. Environ., 77, 173-185, 2001.

Sun, Q. M., Li, Z. Z., Wu, S. L., and Xiao, C. X.: The process of Land Desertification in the Desert and Oasis Transition Belt of Hotan River Basin, J. Arid Land Resour. Environ., 21, 136-141, 2007.

Tang, F. S., Chen, X., Luo, G. P., Lin, Q., and Liu, H. L.: A contrast of two typical LUCC processes and their driving forces in oases of arid areas: A case study of Sangong River Watershed at the northern foot of Tianshan Mountains, Sci. China Ser. D, 50, 65-75, 2007.

Tsegaye, D., Moe, S. R., Vedeld, P., and Aynekulu, E.: Land-use dynamics in Northern Afar rangelands, Ethiopia, Agriculture, Ecosys. Environ., 139, 174-180, 2010. 
Wang, G. Q., Wang, X. Q., Wu, B., and Lu, Q.: Desertification and Its Mitigation Strategy in China, J. Resour. Ecol., 3, 97-104, 2012.

Wang, G. Y., Tiyip, T., and Tang, L. Z.: Social Driven Forces to Land Use Variation in Yu Tian Oasis-Desert Ecotone in Xinjiang, J. Desert Res., 26, 259-263, 2006.

Wang, H. W., Tiyip, T., Ding, J. L., and Luo, J. Y.: Spatial Different Analysis of Land Use/Land Cover Change and Human Impact in Typical Oasis in Arid Land, Computer and Computing Technologies in Agriculture II, Volume 1, IFIP Adv. Informat. Commun. Technol., 293, 388-398, 2009.

Wang, R. and Cheng, G.: The characteristics of water resources, and the changes of the hydrological process and environment in the arid zone of northwest China, Environ. Geol., 39, 783-790, 2000 .

Wang, T.: Progress in sandy desertification research of China, J. Geogr. Sci., 14, 387-400, 2004.

Wang, Y., Xiao, D., and Li, Y.: Temporal-spatial change in soil degradation and its relationship with landscape types in a desert-oasis ecotone: a case study in the Fubei region of Xinjiang Province, China, Environ. Geol., 51, 1019-1028, 2007.

Wang, Y. G. and Li, Y.: Land exploitation resulting in soil salinization in a desert-oasis ecotone, CATENA, 100, 50-56, 2013.

Wei, X. P., Pan. X. Y., Zhao, C. M., Wang, G. X., and Deng, J. M.: Response of Three Dominant Shrubs to Soil Water and Groundwater along the Oasis-Desert Ecotone in Northwest China, Russ. J. Ecol., 39, 475-482, 2008.

Yang, X., Zhang, K., Jia, B., and Ci, L.: Desertification assessment in China: An overview, J. Arid Environ., 63, 517-531, 2005.
Yang, Y., Wang, P., Huang Y., Zhang, Y., and Guo, C.: Assessment of Ecosystem Services Value in Hotan Oasis, Xinjiang, Agr. Sci. Technol., 14, 425-432, 2013.

Yu, B., Stott, P., Di, X. Y., and Yu, H. X.: Assessment of land cover changes and their effect on soil organic carbon and soil total nitrogen in Daqing prefecture, China, Land Degrad. Develop., in press, doi:10.1002/ldr.2169, 2012.

Yu, R., Liu, T., Xu, Yi., Zhu, C., Qu, Z., Liu, X., and Li, C.: Analysis of salinisation of dynamics by remote sensing in Hetao Irrigation District of North China, Agr. Water Manage., 97, 1952-1960, 2010.

Zhang, H., Wu, J. W., Zheng, Q. H., Yu, Y. J.: A preliminary study of oasis evolution in the Tarim Basin,Xinjiang, China, J. Arid Environ., 55, 545-553, 2003.

Zhao, C., Shen, B., Huang, L., Lei, Z., Hu, H., and Yang, S.: A dissipative hydrological model for the Hotan oasis (DHMHO), Water Resour. Manage., 23, 1183-1210, 2009.

Zhao, G., Mu, X., Wen, Z., Wang, F., and Gao, P.: Soil erosion, conservation, and eco-environment changes in the Loess Plateau of China, Land Degradation and Development, in press, doi:10.1002/ldr.2246, 2013.

Zhou, H. H., Chen, Y. N., and Li, W. H.: Soil properties and their spatial pattern in an oasis on the lower reaches of the Tarim River, northwest China, Agr. Water Manage., 97, 1915-1922, 2010.

Zhou, Q., Li, B., and Kurban, A.: Trajectory analysis of land cover change in arid environment of China, Int. J. Remote Sens., 29, 1093-1107, 2008.

Ziadat, F. M. and Taimeh, A. Y.: Effect of rainfall intensity, slope, land use and antecedent soil moisture on soil erosion in an arid environment, Land Degradation and Development, 24, 582-590, 2013. 